\title{
High-strain-rate shear testing applied to titanium
}

\author{
Jan Peirs \\ Supervisor(s): Patricia Verleysen, Joris Degrieck
}

\section{INTRODUCTION}

In this contribution, two experimental techniques to study the dynamic shear behaviour of metals are presented and applied to Ti-6Al-4V. For bulk materials hat-shaped specimens are subjected to a high-strain-rate load in a split Hopkinson compression bar setup. For sheet materials a purpose-developed, novel shear specimen geometry, is loaded in a Hopkinson tensile bar set-up. The value of both techniques to assess the dynamic material behaviour is discussed. Digital image correlation is used to extract the specimen deformation from high speed camera recordings. It is shown that the dynamic behaviour, including fracture of Ti-6Al-4V differs considerably from the static behaviour.

\section{EXPERIMENTAL TECHNIQUES}

\section{A. Bulk materials}

For testing bulk metals, the hat-shaped specimen [1] can be used. In this axissymmetric specimen, shear strains are concentrated in a narrow zone. Figure 1 shows the specimen between the two Hopkinson bars. The region with high shear strains is marked with arrows.

The main advantages of the hat-shaped specimen are that materials are forced to shearing failure and that the deformation is concentrated in a very narrow region which means that very high shear strain-rates are automatically obtained. The technique is thus very suited to study the formation of localized

J. Peirs is with the Materials Science and Engineering Department, Ghent University (UGent), Gent, Belgium, Jan.Peirs@UGent.be shear bands. In addition, the experiment can easily be interrupted by use of the stopper ring so that it is possible to study the shear band and the fracture at different levels of deformation.

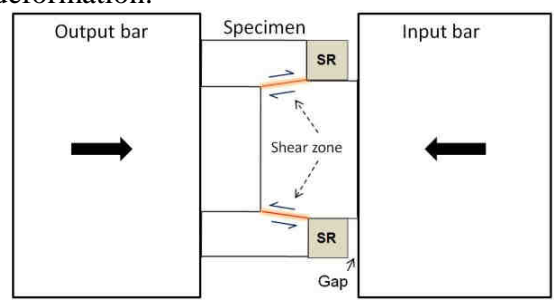

Figure 1: hat-shaped specimen

The disadvantages of the hat-shaped specimen are found in the complex, specimen dimension dependent stress state in the shear region and the impossibility to observe the shear region during the experiment because of its subsurface location.

Results of this experimental technique are presented on the accompanying poster.

\section{B. Sheet materials}

For sheet material testing, a novel sheet shear specimen geometry has been developed using finite element simulations. The specimen is optimised to be appropriate for dynamic testing and to have a pure-shear stress state in the shear region (triaxiality=0). The shear specimen is shown in figure 2 .

The novel feature of this geometry is found in the eccentric position of the notches of the shear region. The centres of the notches do not coincide with the central axis of the specimen. The eccentric location of the notches lowers the stress triaxiality in the shear region (triaxiality $=0$ is pure shear). The 
amount of eccentricity necessary to have a pure-shear stress state dependents on the overall specimen geometry and the mechanical properties.

The specimen does not require a special clamping system, but is instead glued onto the loading bars. In this way, sources of error due to inertia of the clamps, early rupture and buckling at the borders of the shear region and deformation under the clamps are avoided.

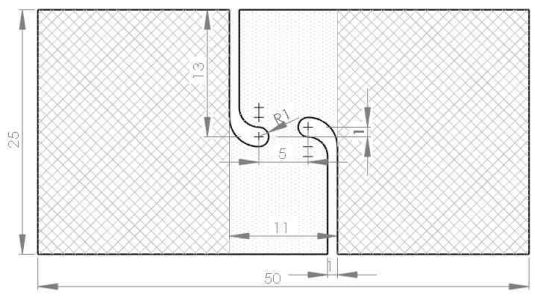

Figure 2: Sheet shear specimen geometry

\section{MATERIAL BEHAVIOUR AND MODELLING}

\section{A. Digital Image Correlation}

Experiments with the sheet shear specimens provide the averaged material behaviour. Digital image correlation (DIC) can be used to determine the local strain. To use this technique, a speckle pattern is applied on the specimen. Evolution of this pattern during deformation of the specimen is captured by a high-speed camera. Figure 3 shows the local strain in the shear region just before fracture of the specimen.

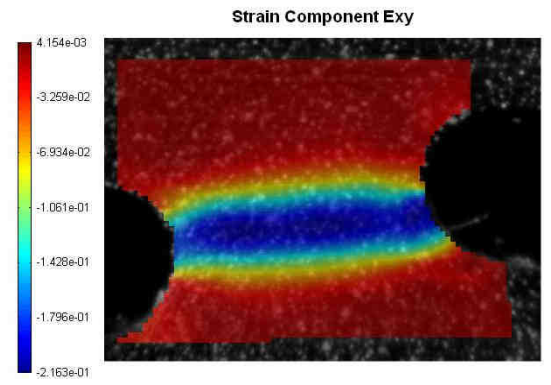

Figure 3: Strain distribution measured by DIC

\section{B. Modelling}

Next to DIC, the local material behaviour is extracted from the experiment by iterative combination of the experimental and simulation data. Figure 4 shows the stressstrain curve extracted from the experiment together with the model.

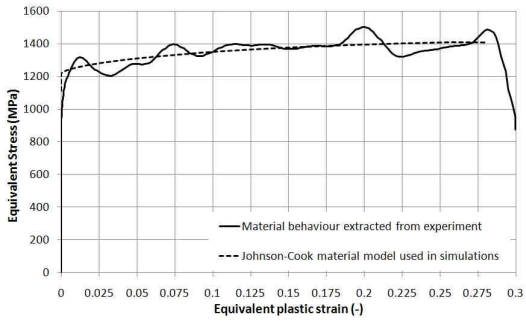

Figure 4: Experiment and Model

\section{CONCLUSIONS}

Different aspects of the high-strain-rate behaviour of Ti-6Al-4V are obtained by two techniques. The tests with hat-shaped specimens are very suited to study the formation of shear bands and the evolution towards fracture. The technique with the sheet specimens is however better to identify material model parameters because of the pure-shear and uniform stress state.

Numerical simulations and digital image correlation lead to a better understanding of the experimental techniques and the established material behaviour.

\section{ACKNOWLEDGEMENTS}

The authors would like to acknowledge the Interuniversity Attraction Poles Programme (IUAP-VI) of the Belgian Science Policy and Prof. W. Van Paepegem for the DIC analysis.

\section{REFERENCES}

[1] Peirs J, Verleysen P, Degrieck J, Coghe F. The use of hat-shaped specimens to study the high strain rate shear behaviour of Ti$6 \mathrm{Al}-4 \mathrm{~V}$. International Journal of Impact Engineering In Press, Corrected Proof 